\title{
Montaigne ensayista argentino: un trabajo editorial de Martínez Estrada
}

\author{
Magdalena Cámpora ${ }^{1}$
}

Resumen. En 1948, Clásicos Jackson edita en Buenos Aires una selección de los Ensayos de Montaigne. Ezequiel Martínez Estrada es el traductor, antólogo y autor de una introducción de noventa páginas que reeditará luego, sin modificaciones, en Heraldos de la verdad (1957), bajo el título "Montaigne, filósofo impremeditado y fortuito". Allí Martínez Estrada, lector de Bergson, de Dilthey y de Driesch, convierte al escéptico y melancólico Montaigne en filósofo vitalista, intuitivo y autodidacta, en consonancia con el esquema de autorrepresentación que había propuesto quince años antes en Radiografía de la Pampa (1933). Este trabajo analiza el modo en que esta "operación Montaigne" legitima la tarea del ensayista argentino, en un momento en que se encuentra bajo el agudo escrutinio de sus pares.

Palabras clave: Legitimación; ensayo latinoamericano; vitalismo; retóricas de la polémica; peronismo.

\section{[en] Montaigne as Argentine Essayist: an Editorial Experience by Martínez Estrada}

\begin{abstract}
Clásicos Jackson" published in 1948, in Buenos Aires, an anthology of Montaigne's Essais selected, presented and translated by Ezequiel Martínez Estrada, with a ninety pages "Estudio Preliminar" that he would later republish, without any changes, in Heraldos de la verdad. Montaigne, Balzac, Nietzsche (1957), under the title "Montaigne, filósofo impremeditado y fortuito". While mentioning contemporary authors such as Bergson, Dilthey and Driesch, Martínez Estrada converts the sceptical and melancholic Montaigne into a vitalist, intuitive, self-taught philosopher that mirrors the self-representation he himself had proposed fifteen years earlier in Radiografía de la pampa (1933). This paper examines the way in which this "operation Montaigne" legitimizes the work of the Argentine essayist, at a time when he is under the sharp scrutiny of his peers.
\end{abstract}

Keywords: Legitimation; Latin-American essay; vitalism; rhetorics of polemic; Peronism.

Sumario. 1. Formas del saber. 2. Un campo de batalla. 3. EME y M.

Cómo citar: Campora, M. (2020) Montaigne ensayista argentino: un trabajo editorial de Martínez Estrada, en Anales de Literatua Hispanoamericana 49, 29-38.

En 1948 -quince años después de la publicación de Radiografía de la pampa (1933), cuando el ensayo de Ezequiel Martínez Estrada recién comienza a encontrar en la Argentina, al decir de Adolfo Prieto, la "recepción sostenida" que lo convertirá poco tiempo después, en los años cincuenta, "en lectura inevitable, en referente, en objeto de vivaz escrutinio" (Prieto 1999: 46)- la colección "Clásicos Jackson" publica, en Buenos Aires, una selección de los Ensayos de Michel de Montaigne a cargo del radiógrafo. "EME" es el traductor, el antólogo y el autor de una introducción de noventa páginas que volverá a publicar en 1957 en Heraldos de la verdad. Montaigne, Balzac, Nietzsche, sin modificación alguna salvo el añadido del título: "Montaigne, filósofo impremeditado y fortuito" (1957: 5-96). Entre estas tres publicaciones: Radiografía de 1933, los Ensayos en Clásicos Jackson del 48 y Heraldos de la verdad del 57, se teje a nuestro entender un proceso de legitimación que se vale de la figura de Montaigne para sostener y reconciliar la "formidable tensión" - la expresión es de Horacio González (1999: 175)- entre las tesis expuestas por Martínez Estrada

\footnotetext{
${ }^{1}$ Centro de Literatura Comparada M. T. Maiorana, Facultad de Filosofía y Letras, Universidad Católica Argentina-CONICET. Buenos Aires. Argentina.

Email: magdalacampora@gmail.com

Este trabajo es parte del Proyecto de Investigación Plurianual "La legitimación del escritor moderno en América Latina y Europa. Polémicas, operaciones, representaciones" (CONICET/UBA).
} 
en Radiografía y su propia pulsión de escritura ensayística. Esa tensión nace de la contradicción implícita entre las premisas estradianas del vacío cultural, del inútil simulacro de europeización de la pampa, y el deseo del (hasta entonces) poeta Martínez Estrada de practicar un género -el ensayo- cuya forma y tradición en la Argentina resultaban justamente de ese denostado simulacro.

En este sentido, pensamos, Montaigne funciona como articulador legitimante entre polos en tensión. Montaigne, o más bien el Montaigne de Martínez Estrada, a quien éste convierte, con tres siglos de distancia, en filósofo vitalista, encarnación viva de un proceso ahistórico de percepción de la realidad similar al que él mismo observaba, unos quince años antes, en la llanura sudamericana. Más aún: en tanto modelo intuitivo y autodidacta de conocimiento que a su vez concuerda con su propio proyecto de escritura, Montaigne le sirve como potente escudo ante las críticas que Radiografía viene recibiendo desde su publicación, en 1933. El melancólico y escéptico Michel Eyquem, atravesado por las lecturas de Bergson, de Dilthey y de Driesch, incorporado a la vivencia orgánica del mundo y emancipado de la autoridad, puede de este modo tácitamente validar la práctica ensayística del argentino, en una relación de homología que trasciende los usuales vínculos de subordinación y jerarquía cultural entre la Argentina y Francia. De esta audaz operación, efectuada en los años cuarenta del siglo pasado, en Buenos Aires, en una colección de divulgación de literatura universal destinada al gran público, quisiéramos ocuparnos en este trabajo.

\section{Formas del saber}

Cuando Martínez Estrada publica, en 1948, durante los primeros años del peronismo, su edición de los Ensayos de Montaigne, su posición en el campo intelectual argentino oscila entre el aislamiento, la automarginación victimizada (Sigal 1996: 378-9) y probablemente la dificultad económica. 1946 es el año en que se jubila del Correo y renuncia a la cátedra de "Literatura universal" que dictaba, desde 1923, en el Colegio Nacional de La Plata (Orgambide 1985: 27). Es, también, el año en que publica en Claridad un Panorama de las literaturas donde, al decir de su ex alumno Anderson Imbert, "habían venido a parar las viejas clases de 1923". ${ }^{2}$ Ese trabajo de divulgación editorial, sintomático quizá de alguna urgencia material, se ve completado con dos colaboraciones para "Clásicos Jackson": los Ensayos de Montaigne (volumen XIII, 1948) y una introducción a las Comedias de Shakespeare (volumen XVI, 1950).

Son, en todo caso y principalmente, trabajos que responden a la militancia autodidacta del autodidacta Martínez Estrada. El Panorama de las literaturas, de 1946, estaba de hecho incluido en la "Biblioteca del autodidacto", colección que respondía a los valores defendidos por Antonio Zamora en Claridad: voluntarismo, honestidad, autoaprendizaje; tales eran -analiza Graciela Montaldo (1999: 37-40)- las columnas de un proyecto pensado para la emancipación cultural de los sectores populares. ${ }^{3}$ Veinte años más tarde, en 1966, en la etapa cubana y con el mismo afán formativo, EME reeditará el Panorama en Editora Pedagógica, en el marco del proyecto Editora Nacional de Cuba.

La poética del autodidacta es a su vez central en la colección "Clásicos Jackson", publicada en Buenos Aires y México, entre 1948 y 1950, por las sucursales latinoamericanas del emprendimiento editorial fundado por Walter Montgomery Jackson a fines del siglo XIX, entre Estados Unidos e Inglaterra (Jackson 1969). Su "Propósito", reiterado al inicio de los cuarenta volúmenes de la colección, presenta el proyecto en estos términos:

Un gran pensador inglés dijo que "la verdadera Universidad hoy día son los libros", y esta verdad, a pesar del desarrollo que modernamente han tenido las instituciones docentes, es en la actualidad más cierta que nunca. Nada aprende mejor el hombre que lo que aprende por sí mismo, lo que le exige un esfuerzo personal de búsqueda y de asimilación; y si los maestros sirven de guías y orientadores, las fuentes perennes del conocimiento están en los libros. ${ }^{4}$

\footnotetext{
${ }^{2}$ En Sur (nro 295, 1965, p. 50), citado por Peter Earle (1996: 59). Emir Rodríguez Monegal por su parte apuntará, en una reseña del Panorama que sale en la revista Marcha, los numerosos errores de un libro que a su entender fue realizado "con excesiva prisa" (1947: 14). La recepción que el Panorama tuvo en el campo letrado parece haber sido más bien crítica; al decir de Bioy, Borges se refería al texto -es cierto que después del 55como "el librito de Historia de todas las literaturas", como la "Historia de parte de su ignorancia" (Bioy Casares [1956] 2006: 163). Christian Ferrer, en su biografía, recopila fabulosos testimonios de la relación tejida con los alumnos que recibieron esas clases (2014: 110-115).

${ }^{3}$ Para un análisis del proyecto de pedagogía cultural de Antonio Zamora en Claridad, ver Montaldo 1987 y 1999 ; Cedro 2013. El catálogo se encuentra en Ferreira de Cassone 2005.

4 "The true University of these days is a Collection of Books" escribe Carlyle en On Heroes, Hero Worship and the Heroic in History (1841).
} 
Esta voluntad didáctica de EME y de los soportes editoriales en los que publica se traslada a Montaigne: "el rasgo sobresaliente de su personalidad", escribe, "es la vocación de educador" (1948: 33). Para Martínez Estrada, esa vocación es reflejo y caución de su propia tarea divulgatoria, que a su vez inscribe en el linaje pionero de formadores argentinos inaugurado por Sarmiento. Una formación que, a imagen del autor de Recuerdos de provincia, está a cargo de quien lee y se sitúa por fuera de las instituciones, como también sucede de hecho en su lectura de Montaigne: "las anécdotas [...] tienden a demostrar, casi, que lo mejor es no entrometerse en el trabajo de autoformación de cada individuo. Cada cual trae su programa de estudios, sus materias predilectas, su texto que aplica según la vida le va ofreciendo oportunidades" (1948: 36). Montaigne en Clásicos Jackson, como parte de la biblioteca del autodidacta, viene en este sentido a confirmar, recursivamente, el movimiento que EME lee en los Ensayos: el de una subjetividad que se emancipa y "desaprende a servir" (I, 20). De la introspección a la intervención política: se cumple aquí la dinámica del ensayo según la cual, como analiza Cristina Kirklighter, "el ensayo se vuelve instrumento que convierte la experiencia privada en crítica de las instituciones sociales y públicas" (2002: 4-5).

Pero el orden de lo real siempre aparece filtrado por la criba del yo, que lleva la materia inicial hacia nuevos parajes, según la bella fórmula en "De la vanité": "j'aime l'allure poétique, à sauts et à gambades" (III, 9: 342). De esos saltos y brincos, Montaigne observa sin demasiado pesar: "Los nombres de mis capítulos no siempre cubren toda la materia; a menudo sólo la denotan con alguna marca" (III, 9: 342). ${ }^{5} \mathrm{La}$ realidad permanece en esa "marca" que la subjetividad luego transforma; una marca que es el eslabón inicial de la asimilación subjetiva y orgánica del mundo, para aprovechamiento propio, para mejora existencial. El texto de la experiencia puede entonces funcionar como modelo para la vida y Michel de Montaigne hablar por el otro; EME: "Montaigne procede como los poetas, revelando en sí pensamientos y sentimientos personales e intemporales: cuanto más subjetivo es, mayor cantidad de otros representa" (1948: 43). En este proceso de autofiguración y de representación se juega el valor cognitivo del ensayo, así como su ejemplar practicidad en el diálogo con el autodidacta, que sólo debe entonces leer los textos puestos a su alcance por la mediación de otro autodidacta, que comparte su experiencia lectora. Esto escribe el lector EME en la "Advertencia" del traductor:

La selección resultó casi enteramente de incluir aquellas páginas y fragmentos de los Ensayos señalados por mí hace mucho tiempo en el texto de Román y Salamero, en lecturas libres de la preocupación de que pudieran servir, más tarde, de guía para otros lectores. Contiene, en consecuencia, lo que personalmente juzgo de mayor interés [...] (yo subrayo, 1948: 99)

Educar mediante el ensayo, unir el ensayo con el juicio personal: como otras formas antiguas de la prosa, el ensayo se plantea históricamente como un saber sobre quien escribe y sobre el mundo. Su forma espontánea, el "ocio de lo infantil" que lo atraviesa y que según Adorno (1958) se resiste a las clasificaciones $\mathrm{y}$ al ordenamiento positivista de las instituciones, desdibuja la especificidad formal y ofrece múltiples oscilaciones temáticas donde el yo ocupa un eje central. Si, para Montaigne, el espíritu es "un cheval échappé" (I, 8: 116), un caballo desbocado que genera monstruos y quimeras, el ensayo trama, mediante un ethos perceptible (y en el caso de Montaigne, infinitamente amigable), la cohesión de un contenido que puede variar indefinida, fragmentariamente. Producir un discurso ensayístico sobre el mundo, escribir para ser publicado, implican entonces también la necesaria y oblicua emergencia de la subjetividad, que asimila y analiza el afuera en una superposición novedosa entre saber y experiencia. ${ }^{6}$ Los Essais instalan de este modo un régimen de inespecificidad factual donde los verificadores de valor de lo dicho son la imaginación, la autenticidad, la condensación, con sus efectos formales: la digresión, la escena indirecta, la metáfora y la imagen, que moldean el concepto.

Esta combinación de imaginación crítica, subjetividad, reflexión abstracta y producción de un saber en diálogo con la época disuelve los límites disciplinares entre literatura, ciencia y filosofía, y da cuenta de la enorme plasticidad y funcionalidad del ensayo en contextos históricos donde la autoridad del campo científico, la institucionalización de las ciencias humanas y la sociabilidad literaria se encuentran en procesos

\footnotetext{
5 "Les noms de mes chapitres n'en embrassent pas toujours la matière; souvent ils la dénotent seulement par quelque marque".

${ }^{6}$ Un ejemplo, entre muchos otros posibles: cuando Montaigne (I, 5) se pregunta si corresponde o no que el comandante de una ciudad sitiada salga de su fortaleza para negociar con el enemigo, propone tanto un saber sobre la guerra a fines del siglo XVI, como su propia experiencia escéptica sobre la moralidad de la política.
} 
de conformación ${ }^{7}$ (Cámpora y Dimópulos 2018). Es ése -según la expresión de Ignacio Sánchez Prado (2019: 55)- el "privilegio epistemológico" de un género al que, en términos históricos, entre mediados del XIX y mediados del XX, acudirán los escritores latinoamericanos en busca de formas que se desarrollan al margen de la institucionalización y de las restricciones metodológicas de cada disciplina.

Ser ensayista, ser autodidacta, educar mediante el ensayo: una línea firme y sutil se dibuja de este modo entre la práctica del ensayo como género libre de artificios institucionales, la materia "Literatura Universal" en La Plata -a cargo de un profesor que no había terminado la escuela secundaria- y Michel de Montaigne. La productividad que el ensayo à la Montaigne le ofrece a EME es, en esta tesitura, grande. Los Essais se despliegan al margen del orden institucional; cuestionan los procesos de construcción del juicio y desnaturalizan los orígenes de la autoridad, tanto política como cognoscitiva. El velo escéptico que en Montaigne desarma la ilusión del mundo, el "artificio del disfraz" (Starobinski 1993: 15) que le hace descreer de las opiniones formadas y de la autoridad consensual, le ofrecen al radiógrafo un espacio de legitimación para su propia, ambiciosa revisión del proyecto modernizador argentino.

Los ensayos que Martínez Estrada selecciona y traduce para Jackson, los que "personalmente juzg[a] de mayor interés" (1948: 99) son en este aspecto elocuentes. Montaigne dio progresivamente, en sucesivas ediciones y campañas de escritura, ${ }^{8}$ ciento siete ensayos a la imprenta; para Clásicos Jackson el argentino traduce cincuenta textos y entre ellos elige las principales reflexiones sobre la constitución del juicio, las motivaciones de los actos, el carácter convenido de la ley: la "Apología de Raimundo Sabunde" (II, 12), "De la inconstancia de nuestras acciones" (II, 1), "De la costumbre y de no cambiar fácilmente los usos recibidos" (I, 23), "De la Soledad" (I, 39), "No gustamos nada puro" (II, 20), "Cómo el sentimiento de los bienes y los males depende en gran parte de la opinión que de ellos tenemos" (I, 14); a su vez traduce la cuasi totalidad del libro tercero, donde Montaigne desnuda, con sutileza y escepticismo, los procesos de formación del juicio, de la opinión, de la verdad comúnmente aceptada: la vanidad de los triunfos mundanos. Martínez Estrada aprovecha estas perspectivas gnoseológicas que por un lado legitiman su cuestionamiento del relato modernizador, y por el otro relativizan su propio polémico posicionamiento como ensayista en el campo literario. El patronazgo es puro: Montaigne encarna un proceso de emancipación de la autoridad externa que irradia sobre su propio posicionamiento díscolo en el campo, más allá de la realidad de los premios y los amigos prestigiosos, Lugones y el "hermano Quiroga"; esa emancipación a su vez resignifica su situación de escritor disidente y crítico del régimen peronista. Desde ahí, pensamos, hay que leer la selección de ensayos sobre la autarquía, la autosuficiencia, la soledad, la vanidad, que funcionan como caución directa de su "sensación insular" (Rest 1968: 49), de su autofiguración como autor marginal y profético, en un tiempo (a fines de los años cuarenta) en que el escritor EME aún se encuentra bajo el foco crítico de aquellos centros de poder simbólico -la revista Sur, pronto los jóvenes "parricidas"- que asignan valor.

\section{Un campo de batalla}

El erudito estudio preliminar de Clásicos Jackson de 1948 sirve, en este sentido, como escudo y como tribuna. Son, estos, los años de la llamada edad de oro del libro argentino, cuando un contexto altamente favorable a la edición ofrece nuevas y dúctiles plataformas para la circulación de ideas: traducciones, prefacios, publicaciones periódicas, armado de colecciones. Y desde esta perspectiva, el espacio paratextual que le ofrece a Martínez Estrada la colección Clásicos Jackson no es una plataforma de respuesta menor. A diferencia de proyectos anteriores (en Tor o Claridad) de divulgación de clásicos de la literatura universal armados por letrados más o menos anónimos, y en consonancia con las operaciones legitimantes que los editores españoles (Losada, Sopena) están poniendo en acto en sus propias colecciones de clásicos universales, Clásicos Jackson presenta un prestigioso "Comité selectivo" asociado al Grupo Sur : Alfonso Reyes, Francisco Romero, Federico de Onís, Ricardo Baeza, Germán Arciniegas constituyen el Comité editorial; colaboran como traductores y antólogos Jorge Luis Borges, Adolfo Bioy Casares, Silvina Ocampo, Guillermo De Torre, Roger Caillois, José Gaos, Rafael Alberti, Francisco Ayala, entre muchos otros. Más

\footnotetext{
${ }^{7}$ Por decirlo de otro modo: en cuanto aparecen regímenes disciplinares y campos específicos, el ensayo pierde sus prerrogativas sobre el todo y se disuelve o-es lo mismo- se especializa.

${ }^{8}$ Ver al respecto Philippe Desan (2002: 297-318).
} 
aun, es probable que el editor y traductor de Montaigne se dirigiera específicamente a ese Comité en su "Estudio preliminar", que ahora vale como apología indirecta de un modo de escribir ensayos y de autorrepresentarse en ellos.

Estamos en 1948: ese año, Ezequiel Martínez Estrada ha publicado Muerte y transfiguración de Martín Fierro, ensayo de interpretación de la vida argentina; en 1946, su Sarmiento; en 1940, La cabeza de Goliat. Quien ofrece un estudio sobre el padre del ensayo es, pues, en 1948, un escritor en pleno ejercicio de la práctica del género. Sin embargo EME se siente indebidamente valorado como ensayista, ${ }^{9}$ sostiene que Radiografía suscitó esa "hostilidad que el psicoanálisis puede denominar defensa de una situación" (1964: 12). Veinticinco años de variadas y sibilinas críticas, inauguradas por la dura reseña de Bernardo Canal Feijóo en 1937, en la revista Sur.

"Radiografías fatídicas" es su irónico título, y es motivada por el Premio Nacional de Literatura que el ensayo recibe cuatro años después de su publicación, y que Canal Feijóo discute. "Los principales valores de [la obra] debían desprenderse de una condición circunstancial y sintomática. [...] Hoy tengo la sensación de que la obra ha quedado clavada en por aquellos días y que el tiempo ha venido marchando desde entonces sin ella" (1937: 64). Una obra fechada, una desactualización respecto del presente: la objeción, que insiste en el vínculo coyuntural con la crisis del treinta, ataca el centro mismo del proyecto de Martínez Estrada, que es la concepción genérica del ensayo como forma de saber no coyuntural, como identificador de "invariantes históricos", siguiendo el modelo Montaigne, que supo "crear para las almas una contemporaneidad que nada tiene que ver con nuestra obcecada contabilidad del tiempo", como escribió en el Panorama de las literaturas (1946: 138).

También reprocha, Canal Feijóo, la excesiva presencia en Radiografía de un yo autoral:

[...] hay obras ante las cuales parece imponerse de un modo perentorio la necesidad [...] de descubrir en su trasfondo la presencia personal del autor, de dosificar humores psicofisiológicos suspendidos en su caldo. No son, nunca, las más grandes. Las más grandes son, infaliblemente, las que más olvidan a su humilde, provisorio, contingente, mágico generador [...] Esta Radiografía de la pampa pertenece a aquella especie de las que parapetan sin el menor misterio a la persona del autor. Párrafo a párrafo el lector va experimentando la no siempre grata ni cómoda presencia del demiurgo literario que la ha urdido (1937: 66)

Diez años más tarde, en el estudio preliminar de Jackson, EME contestará indirectamente ese pedido de impersonalidad, de desincorporación, al observar que la especificidad del ensayo, tal como lo practica Montaigne, pasa por la íntima alianza entre la voz personal y un modo de conocimiento, y que los Essais -la mayor realización histórica del género- viven de esa alianza. Incipit del Estudio preliminar: "El ensayo, tal como lo concebimos hoy, está en Montaigne acabado en punto de perfección" (1948: 9). Así, pues, a las críticas publicadas en Sur, a la atención que él siente le retacean como ensayista -y que pronto vendrá con los textos de Contorno y Ciudad que lo ponen (desde la polémica crítica) en el centro de la escena- contesta afirmando una hermandad de percepción y una homología de escritura nada menos que con el fundador del género, pues su lectura de Montaigne sostiene algo que es perfectamente aplicable a él mismo, y es que el ensayo exige la presencia explícita de esa "personalidad contingente" que sus detractores le cuestionan.

Quienes mejor leen entienden que Montaigne es el núcleo que legitima la operación. Borges, en un áspero intercambio político en 1956, quizá para irritarlo, alude justamente a Montaigne para negarle autenticidad a Martínez Estrada. Lo hace tras la llamada "Revolución Libertadora", cuando explota la conocida polémica en que Martínez Estrada llama a Borges "turiferario a sueldo" y en que Borges lo acusa de simpatías peronistas. ${ }^{10}$ María Celia Vázquez (2011: 87-93) reconstruyó con precisión las implicancias políticas y el desarrollo retórico de ese duelo, donde Borges - para anularlas- convierte las críticas de EME al régimen de Rojas y Aramburu en una supuesta, inexistente afinidad del santafecino con el peronismo. ${ }^{11}$ La disputa

\footnotetext{
${ }^{9}$ Señala Ferrer que la primera edición de RP tardó una década en agotarse. Y más adelante: “muchas declaraciones suyas de este período lo muestran desencantado y mortificado por la poca repercusión de sus libros" (2014: 343).

${ }^{10}$ Sueldos provenientes de los nombramientos recientes de Borges como Director de la Biblioteca Nacional, Miembro de la Academia Argentina de Letras, profesor titular en la Facultad de Filosofía y Letras de la Universidad de Buenos Aires. Ver al respecto Ferrer $2014: 337$.

${ }^{11}$ La publicación de ¿Qué es esto? Catilinaria (Buenos Aires, Lautaro, 1956) poco tiempo antes de la polémica es la mejor prueba del antiperonismo de Martínez Estrada, que además había integrado la comitiva de apoyo a Lonardi de la SADE, tras el golpe de Estado (Fiorucci, 2011: 192). Ese antiperonismo sin fisuras no le impide criticar al régimen de la "Libertadora", en el que ve una forma de "neoperonismo". En marzo de 1956 se publica en Marcha una de las "recientes conferencias en Montevideo que han tenido tanta resonancia", bajo un título que es todo un programa: "Sucesores y albaceas del peronismo" (Marcha, 23 de marzo de 1956, pp. 12-14). En la entrada de 12 de mayo de 1956 del Borges, escribe Bioy:
} 
empieza con intervenciones públicas en Montevideo, en junio de 1956, donde EME muestra sus reparos hacia el régimen de facto, y se cierra con un texto de Borges publicado en Sur, "Una efusión de Martínez Estrada", donde defiende de forma cerrada la "Revolución" y ataca al ensayista, aculándolo desde lo personal, usando en su contra el anterior, deseado patrocinio de Montaigne. En esta polémica, así como en la que tendrá con Sábato ${ }^{12}$ sobre las torturas motivadas por el proceso de "desperonización" impulsado por Aramburu, "Borges no quiere", observa Panesi (2007: 40), "introducir ninguna duda que implique una reticencia a la Revolución Libertadora." Escribirá por ejemplo: "Aramburu y Rojas podrán estar a veces equivocados pero nunca serán culpables". ${ }^{13}$ Estas discusiones reflejan la "crisis del consenso antiperonista" después del 55 (Fiorucci 2011, 175-207): es el momento en que la violencia del tan anhelado nuevo régimen provoca las primeras grietas en el frente intelectual antiperonista; esa violencia es lo que Borges pretende ignorar o minimizar. ${ }^{14}$

La estrategia de desautorización en "Una efusión" consiste en singularizar la disputa, en volverla reyerta entre individuos y no análisis de una situación política marcada por el autoritarismo y la persecución de opositores. Para evitar las críticas, para desviar el tema, Borges arma un ataque mano a mano donde acusa a EME de un procedimiento en él que él mismo excela: la autofiguración. Y para ello recurre, con fina perfidia, a Montaigne:

Desde Montaigne, el escritor propende a dramatizarse, a ser el más tenaz de los personajes creados o proyectados por él. Ese personaje, en el caso de Ezequiel Martínez Estrada, es un profeta bíblico, una especie de sagrado energúmeno. El profeta comporta impíos y malvados que apostrofar y Borges ha sido uno de ellos. No un Borges verdadero o verosímil, naturalmente, sino el Borges que exigen las convenciones del estilo profético. Un Borges tan ficticio como el Perón que es superior a cuantos le precedieron y que inaugura en este país el gobierno técnico, el paso del baqueano al topógrafo. ${ }^{15}(1956: 175)$

La mención a Montaigne es una saeta sigilosa en contra de EME, que había organizado toda su presentación de los Ensayos de 1948 en torno a la veracidad de una voz:

[...] cuando leemos su libro, entendemos que nos ha dejado su imagen escrita, la imagen que en vida se formaba y desvanecía en los espejos [...] Es lo que le dice al rey Enrique III, ante su elogio: "Es preciso que también yo os agrade, porque el libro y yo somos la misma cosa." (1948: 21-22).

[...] el conjunto de los ensayos parciales de [Montaigne] tiene únicamente la unidad que le da la personalidad del autor. Es el documento más completo de la vida intelectual de un hombre [...] se los podría titular: Historia universal de una persona. Es la biografía de un alma nunca satisfecha, sin esperanzas y sin rencores. (1948: 9)

En 1948, Martínez Estrada se arropaba en la figura del ensayista de voz auténtica, y para ello jugaba (eso que Viñas llamaba titeo) con Historia universal de la infamia; en 1956, Borges convierte esa voz en melodrama y máscara. Sin embargo esta idea es contraria a las usuales menciones borgeanas del autor de los Essais; de hecho unos meses más tarde, en 1957, coincidirá con EME al escribir que "Montaigne [...] releyendo sus borradores, reconoció en ellos su voz, el sonido de su alma, y decidió incorporarlos en una

“Los Müller cuentan que Martínez Estrada está medio peronista, medio comunista: en Montevideo habló de la falta de libertad que hay ahora en Buenos Aires; de que todo anda tan mal que no le quedan dudas de que lo mejor sería que volviera Perón.” ([1956] 2006: 162).

${ }^{12}$ Ver Fiorucci 2011: 199-207.

13 “Aramburu y Rojas podrán estar a veces equivocados pero nunca serán culpables. Por eso considero mala la actitud de Martínez Estrada, por ejemplo, que ha dado conferencias, y hecho publicaciones que significan un elogio indirecto de Perón". "Jorge Luis Borges habla de la Argentina", Acción, Montevideo, 4 de junio de 1956, citado por Daniel Martino en nota de su edición del Borges de Bioy (2006: 163).

${ }^{14}$ Panesi (2007: 40) cita la reacción de Borges, narrada por Bioy en la entrada del 29 de junio de 1956, a los fusilamientos de los Generales Valle y Tanco y otros oficiales, y a las ejecuciones de José León Suárez (que Rodolfo Walsh contará en 1957 en Operación masacre): "Viernes, 29 de junio. Comen en casa Borges y Wilcock. Borges: "Hay rumores. A Clemente lo llamaron de no sé dónde. Después la gente se pone sentimental porque fusilan a unos malevos. Qué porquería, los peronistas” ([1956] 2006: 176). Según Ferrer (2014: 336) habría dicho Borges: "Hay que hacer lo que es justo hacer".

15 "Baqueano" y "topógrafo" remiten al artículo de Marcha del 23 de marzo de 1956, donde EME en realidad había escrito: "Se ignora a diestra y siniestra, y esto es gravísimo, que Perón inicia en el país un gobierno de tipo técnico en lugar del gobierno de tipo empírico de sus antecesores. El topógrafo remplaza al baquiano [...] Hay que saber quién ha sido para sentenciarlo y la mayoría de sus acusadores ignoran quién fue." Ver la paráfrasis, hecha con bastante mala fe, de estas ideas en el Borges de Bioy ([1956] 2006: 163), a partir de las cuales Borges arma la referencia en "Una efusión de Martínez Estrada". Difícilmente el artículo de EME en Marcha pueda ser leído como filoperonista. El texto se articula sobre dos ejes: la demanda de un diagnóstico del pasado inmediato (a fin de juzgar tanto a Perón como a sus "sucesores", que para Martínez Estrada representan el "neoperonismo") y la pregunta por las masas como nuevo actor político (una pregunta que, como se sabe, otros intelectuales antiperonistas -Mario Amadeo, Gino Germani- se están haciendo para la misma época). 
obra que fuera su verídica imagen" ([1957] 2003: 38). ${ }^{16}$ En "Una efusión de Martínez Estrada", en cambio, Montaigne es el articulador de la puesta en escena, el postulado de autoridad que convierte a los rivales políticos en farsantes. El giro en la caracterización sin duda revela la voluntad pendenciera: todos fingen, todos actúan, desde ese acto fundador en que el escritor "propende a dramatizarse", "a ser el más tenaz de los personajes creados o proyectados por él". Por eso el EME de Borges impreca, arrastrado por el duelo verbal, cara a cara, en un escenario pasional e íntimo que diluye las circunstancias históricas. Pretender analizarlas lleva según Borges al "laborioso método regresivo" típico de los "comentadores del peronismo" que buscan inscribir los hechos en temporalidades amplias ("necesidades históricas, males necesarios, procesos irreversibles" escribe, parodiando las ideas fuerza de Radiografía de la pampa). A "esos manipuladores de abstracciones" opone "el hombre de la calle" que insulta a "los hijos de perra" con la autoridad que le da el sentido común; todo el desarrollo sorprende si se piensa en su literatura, que es "dinamitación de los órdenes del pensamiento habitual" (Pezzoni 1999: 46). Sobre ese tablado no hay actores políticos colectivos sino enemigos singulares que se enfrentan verbalmente, personajes que dramatizan, apostrofan: "el Borges que exigen las convenciones del estilo profético", Martínez Estrada "sagrado energúmeno", el "evidente Perón". Borges los encierra en el escenario de la disputa teatral, con dejos farsescos, en línea con textos como "L'illusion comique" y "El simulacro" "17; estas máscaras de grotesco criollo por lo demás coinciden con la construcción satírica que Borges viene haciendo del peronismo desde mediados de los años cuarenta, que finamente estudió Annick Louis (2007): irrealidad, farsa, teatralidad.

\section{EME y M}

Pero las observaciones de Martínez Estrada no eran de ese orden: su Montaigne no era máscara, sino modelo ejemplar de una forma de autofiguración, que implicaba a su vez un particular modo de conocimiento. Y aquí es donde se juega la magnitud de su audacia, porque al margen de toda la bibliografía francesa, que conoce, que exhibe al final de su estudio en dos páginas de cerrada tipografía, el radiógrafo propone un Montaigne vitalista cuya fuerza y verdad residen en la intuición auténtica de la mente primitiva. Escribe:

[...] Se mira actuar, se mira pensar, se mira mirándose. El mismo llega a convertirse en objeto de la naturaleza $[\ldots](1948: 21)$

De manera que la inteligencia de Montaigne obtuvo de nuevo el don concedido al primitivo y mantenido en los seres inferiores, de sentir la voz de la naturaleza hablándole a su cuerpo [...] a su vez su vida psíquica adquirió el don de parecerse a la acción, de ser un acto vital, uno de los signos exteriores de la vida, como lo es el calor, la respiración y todo movimiento del cuerpo (1948: 25)

Previsiblemente, Martínez Estrada había seleccionado y traducido los ensayos "americanos" de Montaigne: "Des cannibales" (I, 31), "Des Coches" (II, 12). Allí aparece justamente "el primitivo", personaje conceptual que en los Essais es encarnado por el caníbal: los caníbales -escribe Montaigne- viven fuera de los excesos del racionalismo y "disfrutan la felicidad de una larga vida, tranquila y apacible sin los preceptos de Aristóteles" (II, 12) ${ }^{18}$ son "salvajes", apunta, como son "salvajes los frutos que la naturaleza ha producido de suyo y por curso ordinario" (I, 31). ${ }^{19}$ El movimiento argumental en "Des cannibales" considera que todo juicio proferido sobre ese orden natural americano implica la imposición indebida de una moral externa, artificial, de importación; por eso, porque "nuestro mundo acaba de encontrar a otro" (III, 6), es necesaria la suspensión del juicio ante esa diferencia. Grande es el provecho que el ensayista argentino puede sacar de esa suspensión del juicio, que autoriza una práctica del ensayo sin entramados previos, genealogías o culturas facticias, mientras se nutre del modelo de ensayo que propone Montaigne.

\footnotetext{
${ }^{16}$ El texto es inicialmente publicado en julio de 1957 en Crisis y reeditado en diciembre del mismo año en una plaqueta de 24 páginas titulada Montaigne, Walt Whitman, editada por Colombo en diciembre de 1957, y encargada por Federico Vogelius. Dice el colofón: "De esta obra se han impreso ciento veinte ejemplares en papel B.F.K. Rives, numerados del 1 al 120, que componen la presente edición. La publica para sus amigos Federico Vogelius, en esta Navidad de 1957. En casa de D. Francisco A. Colombo, Buenos Aires".

${ }^{17}$ El primero es publicado en Sur, en el famoso número (237) dedicado a la "reconstrucción nacional", dos meses después del golpe de estado, en noviembre de 1955. El segundo en La Biblioteca, en el primer trimestre de 1957.

18 "Cette response seroit bonne parmy les Canibales, qui jouissent l'heur d'une longue vie, tranquille et paisible sans les preceptes d'Aristote".

19 "Ils sont sauvages, de mesmes que nous appelons sauvages les fruicts que nature, de soy et de son progrez ordinaire, a produicts".
} 
El año de los Ensayos en Jackson es el año de Muerte y trasfiguración del Martín Fierro; allí -afirma María Pía López- "Martínez Estrada se aleja sin demasiada cautela del mundo de las condenas racionalistas. Ese trato proviene del arca sensible que impregna todo el libro: el vitalismo" (2010: 149). Esa misma arca impregna también el Estudio preliminar de los Ensayos. Lector de Bergson, de Driesch y de Dilthey, a quienes cita profusamente, Martínez Estrada pinta un Montaigne que intuye cabalmente el mundo y sus fuerzas profundas por el solo don de sus facultades excepcionales, y de su intuición. Una intuición que permite ver las capas invisibles de la realidad y que coincide con el "ojo del vitalista", que Georges Canguilhem describirá más tarde como "cierta ingenuidad de una visión pretecnológica, prelógica, una visión de la vida anterior a los instrumentos creados por el hombre para extender y consolidad la vida" (1952: 112). Si Montaigne es, según el título elegido para Heraldos, "filósofo impremeditado y fortuito", es entre otras cosas porque encarna "una nueva concepción, un renacimiento del alma a una vida más intensa" (1948: 23). Esa vida no depende por fin de lo externo; en ella "la inteligencia no ha perdido su autonomía, pero comprende mejor que su fuerza proviene de sus sustentáculos naturales y no de los sostenes culturales externos" (1948: 24).

La lectura vitalista del padre del ensayo ofrece una salida de la trampa de la importación cultural, en tanto permite actuar en un lugar sin tradición. A su vez esa lectura vitalista de Montaigne permite su asimilación a la realidad americana porque se trata, justamente, de una visión asociada a la naturaleza: Montaigne ingresa así en el sistema ideológico configurado en Radiografía de la pampa sin negar sus premisas. Cualquiera sea la geografía, para ver la "realidad profunda" es necesario un sujeto que intuya con la fuerza extraordinaria de su introspección aquello que luego se proyecta en el afuera:

Hombre complejo, de laberintos y deltas infinitos, con el ejercicio de su introspección se hizo aún más complejo. A la complejidad propia de su modo de ser, de su mapa, se agregó con los años y el trabajo de buceo, la complejidad de las perspectivas, los timbres, los matices, las resonancias. Al fin de su vida, de sus trabajos de topo resultaba que la primitiva madriguera se había convertido en un dédalo con un mapa de fauna, flora y comunicaciones. A esta altura de su laboriosa complicación, el cosmos entero quedaba representado en esa cartografía. $(1948: 24)^{20}$

Montaigne era ese sujeto, no es el único; otros tendrán ese don de visión: Balzac por ejemplo, que acompaña a Montaigne, junto a Nietzsche, en Heraldos de la verdad, y de quien EME sostendrá, en Realidad y fantasía en Balzac (1964), que posee, como su personaje Facino Cane, el don de intuición o doble vista. En esta apertura a la percepción del mundo que depende del sujeto que escribe, que es constitutiva de los Essais, se dan las condiciones de posibilidad del ensayo americano, y logran conciliarse tres variantes en principio contradictorias: la premisa del vacío cultural, un uso sin impostación de los modelos europeos y la posibilidad misma de existencia del ensayo en la Argentina, donde "todo el porvenir es un resultado de no tener pasado" (1933).

Entonces: a él le incriminan, en Radiografía de la pampa, una desmesurada presencia subjetiva, pero su Montaigne exige que exista una dependencia entre la enunciación personal y la construcción del saber, y esa dependencia implica, a su vez, un yo peculiar, excepcional, vidente, que autoriza ese saber. Excepcionalidad que conlleva signos, marcas de reconocimiento que someramente enuncio: la adultez en la niñez ${ }^{21}$; la profunda soledad; la fecunda capacidad de autogenerarse. Esos signos de Montaigne, Martínez Estrada también los atribuye, en otros lugares de su obra, a sus héroes espirituales: a Guillermo Enrique Hudson niño, a Honoré de Balzac, que "carentes de un conocimiento racional de las cosas, intensifican, al igual que los primitivos y los animales, sus sentidos hasta hacerlos coincidir con el medio" (Sigal 1995: 353). Infancia lúcida y con la mirada del viejo, "niñez recapitulativa, niñez a la inversa" -escribe sobre Montaigne- porque "quien de niño trata a sus padres como desconocidos, de hombre concluye por sentirse hijo de sí mismo" (1948: 12); soledad inevitable, pero soledad plena: "Montaigne es un hombre destinado a la soledad para quien permanecer aislado y en silencio es, más que un gozo y una necesidad de espíritu, la plenitud de su segunda naturaleza" (1948: 10). Cada una de estas marcas también coinciden con las que Martínez Estrada

\footnotetext{
${ }^{20}$ Es notable el diálogo de este texto con el epílogo de El Hacedor (1960).

${ }^{21}$ Infancia lúcida y con la mirada del viejo: es lo que no entiende Canal Feijóo cuando busca señalar la aparente inconsecuencia entre lo que ME define como "alma infantil" y lo que esta logra ver (EME: "alma infantil del hombre maduro de la campaña argentina... [...] es diestra en hallar los rodeos morosos que la dejan en descubierto (a la personalidad)" por lo que observa Canal: "Y esta existencia alerta y sin párpados, y esta destreza en descubrir los infragantis de la personalidad ajena, ¿son atributos de un alma infantil?” Sur 1937: 69).
} 
atribuye al intelectual americano (en particular en Para una revisión de las letras argentinas); son también sería materia de otro trabajo- las que lee en su propia historia. ${ }^{22}$

De la aceptación o la negación de esa dependencia entre sujeto y saber depende la validación o la invalidación de todo el sistema estradiano. Así lo leerá con lucidez Fernand Braudel en una reseña sobre Radiografía publicada en 1948, en los Annales: «Et que pour de longues années encore, tout intellectuel de ces pays jeunes ne peut se comprendre lui-même qu'en comprenant son pays, en se l'expliquant à lui-même et aux autres. L'Argentine d'Ezequiel Martínez Estrada, c'est Ezequiel Martínez Estrada lui-même" (1948: 438). Asimismo, tal como le sucedía a Montaigne, la forma inespecífica del ensayo resulta de su personalidad, encuentra en ella su justificación: "Como él, [el ensayo] es un ser proteico, amorfo, susceptible de transformarse hasta adquirir un cuerpo vivo, una cara, una voz. Su estilo es igual a su pensamiento y nos parece imposible que hubiera podido expresarse en ninguna de las formas tradicionales para la prosa y el verso, que imponían pautas y leyes de juego previas" (Martínez Estrada, 1948: 27).

Que la coherencia interna del sistema expositivo del ensayo, que la forma del ensayo según Martínez Estrada requieran -como lo requería Montaigne- la opción personal, es su privilegio genérico, que le permite construirse sin pasar por las horcas caudinas de la filosofía y de la ciencia, ni acatar sus exigencias disciplinares. En todo este proceso Montaigne funciona como referencia, nunca en relación jerárquica, nunca como influencia. Es una relación de relevancia, un orden cardinal, un punto de orientación. La perspectiva adoptada por Martínez Estrada respecto de Montaigne obliga de esta forma a salir de lo que François Noudelmann llama "el paradigma genealógico" (2004), en la medida en que supone, con hidalguía, un proceso vital y cognoscitivo homólogo, de pares, que estaría sosteniendo por igual la experiencia de escritura de los Essais y de Radiografía de la pampa.

\section{Referencias bibliográficas}

AA.VV. (1996). Segundo Congreso Internacional sobre la Vida y la Obra de Ezequiel Martínez Estrada. Bahía Blanca: Fundación Ezequiel Martínez Estrada.

Bioy Casares, Adolfo (2006). Borges. Barcelona: Destino.

Borges, Jorge Luis (1955), "L'illusion comique", Sur, 237 (1955), p. 9.

Borges, Jorge Luis (1956), "Una efusión de Martínez Estrada", Sur, 242 (1956), pp. 52-53.

Borges, Jorge Luis (1957), "El simulacro", La Biblioteca, 9. 1 (enero-marzo 1957), pp. 116-117.

Borges, Jorge Luis (1957), "Montaigne, Walt Whitman", Crisis (julio 1957), reeditado en plaqueta: Montaigne, Walt Whitman. Buenos Aires: Francisco A. Colombo.

Canal Feijóo, Bernardo (1937), "Radiografías fatídicas", Sur, 37 (1937), pp. 63-77.

Braudel, Fernand (1948), "La règle du jeu”, Annales. Économies, Sociétés, Civilisations, 4 (1948), pp. 437-438.

Cámpora, Magdalena y Dimópulos, Mariana (2018), "El centauro de los géneros, hoy. Apuntes sobre el ensayo en Argentina y México, 2000-2015", Insula: revista de letras y ciencias humanas (coord. Ana Gallego Cuiñas), 859860 (2018), pp. 49-52.

Canguilhem, Georges (1962). La connaissance de la vie. Paris: Hachette.

Desan, Philippe (2002). Montaigne dans tous ses états. Fasano: Schene Editore.

Earle, Peter (1996), "Martínez Estrada, nuestro lector", en Segundo Congreso Internacional sobre la Vida y la Obra de Ezequiel Martínez Estrada. Bahía Blanca: Fundación Ezequiel Martínez Estrada, pp. 55-60.

Ferreira de Cassone, Florencia (2005). Índice de "Claridad": una contribución bibliográfica. Buenos Aires: Dunken.

Ferrer, Christian (2014). La amargura metódica. Vida y obra de Ezequiel Martínez Estrada. Buenos Aires: Sudamericana.

Fiorucci, Flavia (2011). Intelectuales y peronismo. 1945-1955. Buenos Aires: Biblos.

González, Horacio (1999). Restos pampeanos. Ciencia, ensayo y política en la cultura argentina del siglo XX. Buenos Aires: Colihue.

Kirklighter, Cristina (2002). Traversing the democratic borders of the essay. Albany: State University of New York Press.

Louis, Annick (comp.) (1999). Enrique Pezzoni, lector de Borges: lecciones de literatura, 1984-1988. Buenos Aires: Editorial Sudamericana.

Louis, Annick (2006). Borges face au fascisme, 1. Les causes du présent. Paris: Aux lieux d'être.

Louis, Annick (2007). Borges face au fascisme, 2. Les fictions du contemporain. Paris: Aux lieux d'être.

${ }^{22}$ En carta a Victoria Ocampo: "el triste privilegio de comprender las cosas/ de la vida con precoz claridad de adulto". 
Martínez Estrada, Ezequiel (1996) [1933]. Radiografía de la Pampa. Leo Pollman (ed.). México DF: ALLCA XX, Col. Archivos.

Martínez Estrada, Ezequiel (1946). Panorama de las literaturas. Buenos Aires: Claridad.

Martínez Estrada, Ezequiel (1948). Michel de Montaigne. Ensayos, traducción y prólogo. Buenos Aires: Clásicos Jackson, vol. XIII.

Martínez Estrada, Ezequiel (1957), "Montaigne, filósofo impremeditado", en Heraldos de la verdad. Buenos Aires: Nova, pp. 7-96.

Martínez Estrada, Ezequiel (1964). Realidad y fantasía en Balzac. Bahía Blanca: Universidad Nacional del Sur.

Montaigne, Michel de (2002). Essais. Ed. Jean Céard. Paris: LGF.

Montaldo, Graciela (1987), "La literatura como pedagogía, el escritor como modelo", Cuadernos hispanoamericanos, 445 (julio 1987), pp. 41-64.

Montaldo, Graciela (1999), "La disputa por el pueblo: revistas de izquierda”, en Saúl Sosnowski (ed.). La cultura de un siglo: América latina en sus revistas. Madrid: Alianza editorial, pp. 37-50.

Noudelmann, François (2004). Pour en finir avec la généalogie. Paris: Léo Scheer.

Orgambide, Pedro (1985). Genio y figura de Ezequiel Martínez Estrada. Buenos Aires: EUDEBA.

Panesi, Jorge (2007), "Borges y el peronismo", en Guillermo Korn (Comp.). El peronismo clásico (1945-1955). Descamisados, gorilas y contreras. Buenos Aires: Paradiso, pp. 30-41.

Prieto, Adolfo (1999), "Radiografía de la pampa: configuración de un clásico”, en Carlos Altamirano (editor). La Argentina en el siglo XX. Buenos Aires: Ariel, pp. 44-55.

Rest, Jaime (1968), "Trayectoria de Martínez Estrada", en AA.VV. Homenaje a Ezequiel Martínez Estrada. Bahía Blanca: Universidad Nacional del Sur.

Rosales Rodríguez, Amán (2017), "Ensayo y vida. El significado de Montaigne para Ezequiel Martínez Estrada”, Études romanes de Brno, 38 (2017), pp. 1-16.

Rodríguez Monegal, Emir (1947), "Panorama de las literaturas”, Marcha, 372 (marzo 1947), p.14.

Rodríguez Monegal, Emir (1956), "Martínez Estrada o la toma de conciencia", en El juicio de los parricidas. La nueva generación argentina y sus maestros. Buenos Aires: Deucalión, cap. 1.

Rubione, Alfredo (1980), "Ezequiel Martínez Estrada", en Historia de la literatura Argentina. Buenos Aires: CEAL, pp. 505-528.

Sánchez Prado, Ignacio (2019), "The Alphonsine Literary Form: Idealism, Modernism and the Essay”, en Cantú, Roberto (ed.). A Scholiast's Quill: New Critical Essays on Alfonso Reyes. Cambridge: Cambridge Scholars Publishing, pp. 52-71.

Sebreli, Juan José (1967). Martínez Estrada, una rebelión inútil. Buenos Aires: Jorge Álvarez ed.

Sigal, León (1996), "Itinerario de un autodidacta", en Ezequiel Martínez Estrada. Radiografía de la Pampa [1933]. Ed. Leo Pollman. México DF: ALLCA XX, Col. Archivos, pp. 349-383.

Starobinski, Jean (1993). Montaigne en mouvement. Paris: Gallimard.

Vázquez, María Celia (2011), "Peronismo, pobreza y retórica (Martínez Estrada vs. Borges y la yapa: la respuesta de Jauretche)", en Intervenciones intelectuales en el contexto del peronismo clásico. Bahía Blanca: EDIUNS, pp. 87108.

Viñas, David (1996), “Martínez Estrada: de Radiografía de la Pampa hacia el Caribe”, en Ezequiel Martínez Estrada. Radiografía de la Pampa. Ed. Leo Pollman. México DF: ALLCA XX, Col. Archivos, pp. 409-423.

W.M. Jackson, INC. Editores (1969). Historia de la casa Jackson. Barcelona: Garriga Impresores. 